\title{
Racial/Ethnic Variability in Diabetes Mellitus among United States Residents Is Unexplained by Lifestyle, Sociodemographics and Prognostic Factors
}

\author{
Laurens Holmes Jr., ${ }^{1,2}$ Jobayer Hossain, ${ }^{3}$ Doriel Ward, ${ }^{4}$ and Franklin Opara ${ }^{1}$ \\ ${ }^{1}$ American Health Research Institute, Houston, TX 77008, USA \\ ${ }^{2}$ Office of Health Equity Plus Inclusion, Nemours/A.I. duPont Children Hospital, Wilmington, DE 19803, USA \\ ${ }^{3}$ Nemours Biomedical Research, Wilmington, DE 19803, USA \\ ${ }^{4}$ Christiana Care Health System, Wilmington, DE 19899, USA \\ Correspondence should be addressed to Laurens Holmes Jr., lhol@ahriresearch.org \\ Received 5 February 2012; Accepted 26 February 2012 \\ Academic Editors: C. M. Buchalla and C. Castro
}

Copyright ( $\odot 2012$ Laurens Holmes Jr et al. This is an open access article distributed under the Creative Commons Attribution License, which permits unrestricted use, distribution, and reproduction in any medium, provided the original work is properly cited.

Background. The mortality and prevalence of diabetes mellitus (DM) vary across racial/ethnic groups with African Americans/blacks being disproportionately affected. However, it is unclear to what extent such disparities persist after the adjustment for covariates related to race/ethnicity and/or DM in the population. We aimed to assess racial/ethnic disparities in DM and to determine which covariates account for the observed racial/ethnic variabilities. Materials and Methods. We utilized a large cross-sectional survey of the US noninstitutionalized residents $(n=30,852)$ to investigate the racial/ethnic disparities in diabetes mellitus, and the degree in which the disparities are explained by the relevant covariates. Pearson's chi-square was used to examine study variables by race/ethnicity, while logistic regression was used to assess the effect of race/ethnicity and other covariates on DM prevalence. Results. There were statistically significant ethnic/racial differences with respect to income, education, marital status, smoking, alcohol, physical activities, body mass index, and age, $p<0.05$, but not insurance coverage, $p>0.05$. Race/ethnicity was a single independent predictor of DM, with African Americans (non-Hispanic blacks) more likely to be diagnosed for DM compared with non-Hispanic whites, prevalence odds ratio (POR) 1.45, 95\% confidence interval (CI) 1.30-1.62, while Hispanics were less likely to be diagnosed, POR $=0.98,95 \%$ CI 0.87-1.09. Similarly, after controlling for potential confounders, the racial/ethnic variability in DM between AA/blacks and non-Hispanic whites persisted, adjusted POR = 1.30, 95\% CI 1.15-1.47. Conclusions. Racial/ethnic variability exists in DM prevalence and is unexplained by racial/ethnic variance in education, income, marital status, smoking, alcohol, physical activities, age, and sex.

\section{Introduction}

Diabetes mellitus (DM) is one of the leading causes of death and disability in the United States, placing a significant public health burden both on individuals with DM as well as on the US health care system [1-6]. Type 2 DM accounts for approximately 90 to $95 \%$ of all diagnosed cases of diabetes and the rest are type I DM (NIDDK, 2005) [1].

According to national statistics, DM was the sixth leading cause of overall death listed on US death certificates in 2002, while by race/ethnicity, it was the 4th leading cause of death for non-Hispanic blacks, 5th for Hispanic and 6th for
non-Hispanic white [1, 5-9]. Like mortality, the prevalence of DM also varies by race and ethnicity. The age-adjusted prevalence rate of diagnosed DM in 2005 among the US population of age 20 years or more was $9.5 \%$, while this rate was $13.3 \%$ in non-Hispanic blacks, $8.7 \%$ in non-Hispanic whites, and 9.5\% in Hispanic [1, 3, 4, 8-11]. These data clearly reveal variations in the racial/ethnic distribution of diabetes mellitus. African Americans are disproportionately at risk for DM and have the highest prevalence compared to other racial/ethnic groups [12-18]. The biological risk factors of DM include overweight or obesity, family history of DM (genetic factor), gestational diabetes, high blood 
pressure, abnormal cholesterol (lipid) levels, and physical inactivity $[1,3,4,12,19,20]$. However, the racial disparity of DM may be attributable to variations in the distribution of specific risk factors, and these risk factors may differ by race/ethnicity [3-12]. Explanatory factors for racial/ethnic differences in DM include differences in race/ethnicity family income and insurance status. Other predictors of DM include socioeconomic, demographic, and prognostic factors [3, 4, 16-18, 21, 22].

This present study was designed to examine the nexus between race and DM, using the National Interview Health Survey (NIHS) data, and to determine whether or not the observed variance could be explained by the racial/ethnic disparities in insurance coverage, income, education, and other socioeconomic parameters that defined racial/ethnic group in the US. We postulate that the racial/ethnic disparities in DM may be explained by ethnic and racial variance in income, insurance status, educational attainment, and related socioeconomic, demographic, and prognostic risk factors.

\section{Methods}

After an IRB approval from the American Health Research Institute (AHRI), we conducted a cross-sectional study to examine racial/ethic variability in the prevalence of DM among noninstitutionalized US residents. Specifically, this study utilized secondary data to examine the relationship between the outcome variable: diabetes mellitus and main predictor variables: race, family income, insurance status and other sociodemographic and prognostic variables: age, sex, education level, employment status, marital status, body mass index (BMI), cigarette smoking, physical activity, and alcohol drinking status.

\section{Study Population}

The sample of the NHIS, 2003, consisted of 30,852 adults. Participants were non-Hispanic whites, $n=20,169$ (65.37\%), non-Hispanic blacks, $n=4,168$ (13.51\%), Hispanics, $n=5,416(17.55 \%)$, and others, $n=1,099(3.56 \%)$. Participants were either male, $n=13,427$ (43.52\%), or female, $n=17,425$ (56.48\%), with ages of 18 years and older.

\section{Data Collection and Sampling Techniques}

4.1. Data Collection Procedures. Data were collected via a personal household interview by census interviewers. The details of the sampling are published elsewhere [23].

\section{Study Variables}

5.1. Outcome Variable. The study outcome variable (diabetes mellitus) was measured as a self-reported variable and was dichotomized as "yes" and "no." Subjects were asked if they were ever told by their health care provider of having diabetes mellitus.
5.2. Main Predictor (Explanatory) Variable. The main predictor variable for this study was race/ethnicity and was categorized into non-Hispanic whites, non-Hispanic blacks, Hispanics, and others.

\section{Other Potential Explanatory Variables}

Insurance coverage was measured by any family members having insurance coverage and was categorized into "yes," "no," "refused," "not ascertained," and "do not know." The responses "refused," "not ascertained," and "do not know," because of the small numbers, were not included in the analysis. Income was measured by family income greater than $\$ 20,000$ and less than $\$ 20,000$. This variable was categorized into "greater than \$20,000," "less than \$20,000," "refused," "not ascertained," and "do not know." Similarly, the responses "refused," "not ascertained," and "do not know" were not included in the analysis.

The sociodemographic variables were age, sex, education level, employment status, and marital status. The age of participants was originally measured as a continuous variable and later categorized into a binary scale $\geq 50$ years versus $<50$ year) variable given the clinical relevance of age in the predisposition to diabetes mellitus. Both males and females were eligible for the survey provided the age requirement was satisfied.

Education level was measured by the years of school attainment. This variable was collected as categorical but was recoded for suitable categories in comparing "less than or equal to high school," "some college," and "greater than or equal to a bachelor's degree." Employment status was measured by a categorical variable that elicited information on job profile. This variable was recoded in order to examine unemployment versus employment, with respect to racial distribution and the association with the outcome variables. Marital status was measured by a categorical variable and was used as social support system proxy to examine the influence of this variable on the outcome variable, diabetes mellitus.

6.1. Prognostic Variables. Body mass index (BMI) was conceptualized by the relationship between height and weight. This variable was collected on a continuous scale and was recoded into four distinct categories to reflect normal BMI and overweight BMI, utilizing the Centers for Disease Control and Prevention's cut-off points for BMI. Smoking was conceptualized as history of tobacco use. This variable was collected as categorical with the main variable eliciting information on "ever smoked" and "never smoked." The responses "refused," "not ascertained," and "do not know" were not included in the analysis. This variable was recoded into a binary variable. Physical activity was measured by frequency of exercise. This variable was categorized into ten groups with major categories including "never exercise," "exercise" and "unable to exercise." This variable was recoded into "ever exercise" (including daily, weekly, monthly, and yearly basis) versus "never exercise" (including unable to exercise), in order to examine the outcome variables and the association with race. Alcohol drinking status is collected as a categorical variable and is measured by the number of 
drinks within a period of time. This variable was recoded into "lifetime abstainer," "former drinker," and "current drinker." This variable was used as confounding and was controlled in the association between race/ethnicity and diabetes mellitus.

6.2. Statistical Analyses. Categorical variables were summarized using frequency and percentages, while continuous variables were summarized using mean and standard deviation, or median and interquartile range (IQR) if normality assumption was violated. Pearson's chi square statistic was used to examine the racial/ethnic association between DM and race/ethnicity. Similarly, the distribution of the predictor variables by race/ethnicity was obtained using chi-square statistic. The crude association between the main predictor variable race/race and diabetes mellitus was assessed using unconditional univariable logistic regression model. In addition, multivariable logistic regression model was used to simultaneously adjust for the confounding effects of the potential confounding variables on the association between race/ethnicity and diabetes mellitus. To enter into the multivariable model, a variable was required to be significant at $p<0.25$ or $p<0.10$ for an interaction. Further, variables with biological or clinical relevance were entered into the multivariable model. All tests were two-tailed, and the significance level was $p<0.05$. The entire analysis was performed using STATA statistical software version 10.0. (STATACorp, College Station, TX).

\section{Results}

There were 30,852 participants, in which less than 4\% were others, implying other racial/ethnic group in the United States population besides Caucasian (non-Hispanic white), African American (non-Hispanic black), and Hispanic. The majority of the study participants were non-Hispanic whites, $n=20,169(65.4 \%)$. The remaining racial/ethnic groups were non-Hispanic blacks, $n=4,168$ (13.5\%), and Hispanics, $n=5,416$ (17.5). Though not shown in the table, the overall prevalence of diabetes mellitus was $8.3 \%$ in this sample of noninstitutionalized United States adult residents.

Table 1 presents the study characteristics by race/ethnicity. There were statistically significant ethnic/racial differences with respect to education, family income, marital status, current smoking status, history of alcohol use, physical activity, body mass index (BMI), and age group, $p<0.05$. However, there were no statistically significant racial differences regarding insurance status, $p>0.05$. Compared to Caucasians, African Americans and Hispanics were less likely to acquire undergraduate and graduate degrees (9.2\% versus $4.5 \%$ and $3.1 \%$, resp.). Family income was significantly higher among non-Hispanic whites (72.5\%) compared with African Americans (55.1\%) and Hispanics $(57.7 \%)$. In addition, Hispanics $(31.1 \%)$ were less likely to smoke compared to African Americans (37.7\%) and non-Hispanic whites (47.9\%). Non-Hispanic whites $(65.8 \%)$ were more likely to report alcohol use compared to African Americans (49.3\%) and Hispanics (51.1\%). Further, Hispanics $(20.1 \%)$ were less likely to exercise compared with African Americans (24.6\%) and non-Hispanic whites $(28.8 \%)$. Non-Hispanic whites $(21.7 \%)$ were less likely to be overweight compared to African Americans (33.5\%) and Hispanics $(25.1 \%)$. Furthermore, compared to African Americans (54.9\%) and non-Hispanic whites (64.1\%), Hispanics $(42.3 \%)$ were less likely to be in the older age group ( $>50$ years).

Table 2 shows the racial/ethnic variability in DM prevalence. The race nonspecific (overall) prevalence of diabetes mellitus was $8.3 \%$. There were statistically significant racial/ethnic disparities in the prevalence of DM, $\chi^{2}(3, N=$ $30,852)=49.1, p \leq 0.001$. The Caucasians $(7.8 \%)$ compared to African Americans (11.0\%) were less likely to report being diagnosed with diabetes mellitus, but Hispanics were not.

Table 3 illustrates the crude or unadjusted association between race/ethnicity and diabetes mellitus. There was a statistically significant difference in the prevalence of diabetes mellitus by race/ethnicity. Relative to Caucasians, African Americans were most likely to be diabetic, prevalence odds ratio $(\mathrm{POR})=1.45$, and 95\% confidence interval (CI) 1.30 1.62 , but Hispanics were not, $\mathrm{POR}=0.98$, 95\% CI $0.87-$ 1.09. Family income, education, age, body mass index, smoking, alcohol, physical activities, and marital status were statistically significantly associated with DM prevalence, $p<$ 0.05 , but insurance status was not, $\mathrm{POR}=1.0,95 \% \mathrm{CI}$ 0.88-1.44. Educational attainment inversely correlated with the prevalence of diabetes mellitus and clearly depicted a dose response pattern. Relative to less than high school education, high school education was $61 \%$ associated with DM prevalence reduction, $\mathrm{POR}=0.39,95 \%$ CI $0.36-0.42$. Likewise, relative to less than high school, some college educational background was associated with $78 \%$ reduction in the prevalence of DM, POR $=0.22,95 \%$ CI $0.19-0.25$. The residents with bachelors and advanced degrees were $80 \%$ less likely to be diabetic compared to those with less than high school education, $\mathrm{POR}=0.20,95 \%$ CI $0.17-0.24$.

Table 4 presents the unconditional multivariable logistic regression model of the effect of race/ethnicity on diabetes mellitus after controlling for family income, education, age, BMI, smoking, alcohol history, physical activities, and marital status. After controlling for these covariates, the statistically significant increase in the prevalence of DM among African Americans, compared to Caucasians persisted, adjusted POR $=1.30,95 \%$ CI 1.15-1.47.

\section{Discussion}

Previous studies have shown the variations in DM prevalence by race/ethnicity. In this current study, we aimed at assessing the covariates that may possibly explain the disparities of DM prevalence between Caucasians and African American/blacks as well as Hispanics. Primarily, this study clearly demonstrated that racial/ethnic variation in diabetes mellitus between African Americans and Caucasians exists and is not explained by the differences in the distribution of family income, education, marital status, alcohol history, physical activities, body mass index, age, and smoking history. 
TABLE 1: Study characteristics comparing covariates by race/ethnicity in a sample of community-based United States residents.

\begin{tabular}{|c|c|c|c|c|c|c|c|c|c|c|}
\hline \multirow{2}{*}{ Variables } & \multicolumn{2}{|c|}{ Caucasian } & \multicolumn{2}{|c|}{ African American } & \multicolumn{2}{|c|}{ Hispanic } & \multicolumn{2}{|c|}{ Others } & \multirow{2}{*}{$\begin{array}{l}\chi^{2} \\
(\mathrm{df})\end{array}$} & \multirow{2}{*}{$p$} \\
\hline & $n$ & $\%$ & $n$ & $\%$ & $n$ & $\%$ & $n$ & $\%$ & & \\
\hline Education & & & & & & & & & $1800.0(9)$ & $<0.001$ \\
\hline$<$ High school & 8672 & 43.0 & 2257 & 54.2 & 3852 & 71.1 & 368 & 33.5 & & \\
\hline High school & 6090 & 30.2 & 1278 & 30.7 & 1046 & 19.3 & 277 & 25.2 & & \\
\hline Some college & 3559 & 17.6 & 444 & 10.6 & 352 & 6.5 & 259 & 23.6 & & \\
\hline$\geq$ Bachelor's degree & 1848 & 9.2 & 189 & 4.5 & 166 & 3.1 & 195 & 17.7 & & \\
\hline Income & & & & & & & & & $772.3(3)$ & $<0.001$ \\
\hline$\leq \$ 20,000$ & 5,547 & 27.5 & 1,872 & 44.9 & 2,290 & 42.3 & 301 & 27.4 & & \\
\hline$>\$ 20,000$ & 14,622 & 72.5 & 2,296 & 55.1 & 3,126 & 57.7 & 798 & 72.6 & & \\
\hline Marital status & & & & & & & & & $744.0(3)$ & $<0.001$ \\
\hline Married & 9,407 & 46.6 & 2,895 & 69.5 & 2,566 & 47.4 & 505 & 46.0 & & \\
\hline Nonmarried & 10,762 & 53.4 & 1,273 & 30.5 & 2,850 & 52.6 & 594 & 54.0 & & \\
\hline Insurance status & & & & & & & & & $4.3(3)$ & 0.222 \\
\hline Yes & 18,005 & 89.3 & 3,717 & 89.2 & 4,799 & 88.6 & 996 & 90.6 & & \\
\hline No & 2,164 & 10.7 & 451 & 10.8 & 617 & 11.4 & 103 & 9.4 & & \\
\hline Current smoking status & & & & & & & & & $673.9(3)$ & $<0.001$ \\
\hline Yes & 9,666 & 47.9 & 1,572 & 37.7 & 1630 & 30.1 & 347 & 31.6 & & \\
\hline No & 10,503 & 52.1 & 2,596 & 62.3 & 3,786 & 69.9 & 752 & 68.4 & & \\
\hline Alcohol history & & & & & & & & & $660.5(2)$ & $<0.001$ \\
\hline Yes & 13,277 & 65.8 & 2,054 & 49.3 & 2,767 & 51.1 & & & & \\
\hline No & 6,892 & 34.2 & 2,114 & 50.7 & 2,649 & 48.9 & & & & \\
\hline Physical activity & & & & & & & & & $182.0(3)$ & $<0.001$ \\
\hline Yes & 5,816 & 28.8 & 1,025 & 24.6 & 1,087 & 20.1 & 323 & 29.4 & & \\
\hline No & 14,353 & 71.2 & 3,143 & 75.4 & 4,329 & 79.9 & 776 & 70.6 & & \\
\hline Body mass index & & & & & & & & & $575.3(9)$ & $<0.001$ \\
\hline Underweight & 421 & 2.2 & 47 & 1.2 & 62 & 1.22 & 53 & 5.1 & & \\
\hline Normal weight & 7,812 & 40.8 & 1,169 & 29.9 & 1,782 & 35.0 & 588 & 56.0 & & \\
\hline Overweight & 6,776 & 35.3 & 1,384 & 35.4 & 1,969 & 38.7 & 289 & 27.6 & & \\
\hline Obese & 4,152 & 21.7 & 1,307 & 33.5 & 1,280 & 25.1 & 119 & 11.3 & & \\
\hline Age group & & & & & & & & & $927.7(3)$ & $<0.001$ \\
\hline$\leq 50$ years & 7244 & 35.9 & 1,878 & 45.1 & 3,125 & 57.7 & 585 & 53.2 & & \\
\hline$>50$ years & 12,925 & 64.1 & 2,290 & 54.9 & 2,291 & 42.3 & 514 & 46.8 & & \\
\hline
\end{tabular}

TAвLE 2: The comparison of diabetes mellitus by race/ethnicity in a sample of community-based United States residents.

\begin{tabular}{|c|c|c|c|c|c|c|c|c|c|c|}
\hline \multirow{2}{*}{ Variables } & \multicolumn{2}{|c|}{ Caucasian } & \multicolumn{2}{|c|}{ African american } & \multicolumn{2}{|c|}{ Hispanic } & \multicolumn{2}{|c|}{ Others } & \multirow{2}{*}{$\chi^{2}(\mathrm{df})$} & \multirow[b]{2}{*}{$p$} \\
\hline & number & $\%$ & number & $\%$ & number & $\%$ & number & $\%$ & & \\
\hline Diabetes mellitus & & & & & & & & & $49.1(3)$ & $<0.001$ \\
\hline Yes & 1,580 & 7.8 & 459 & 11.0 & 415 & 7.7 & 90 & 8.2 & & \\
\hline No & 18,589 & 92.2 & 3,709 & 89.0 & 5,001 & 92.3 & 1,009 & 91.8 & & \\
\hline
\end{tabular}

Notes and abbreviations: the significance level is $<0.01$, df: degree of freedom, \%: percentage.

Our results confirm previous studies on high prevalence of DM among African Americans in our unadjusted and controlled models $[1,2,8,9,12-14,16-18,20,22]$.

We have demonstrated that income is an independent predictor of diabetes mellitus. Caucasians presented with a higher family income level compared with African Americans/blacks and Hispanics. However, diabetes mellitus prevalence was not higher among Hispanics compared to Caucasians in both our crude and adjusted models. Whereas family income predicts diabetes mellitus prevalence among African Americans, similar claims could not be made of the Hispanics relative to Caucasians [7, 21-28].

Our results indicate that education level inversely correlates with diabetes mellitus prevalence. This finding is 
TABLE 3: Unconditional univariable logistic regression model of the effect of race/ethnicity and other factors on the prevalence of diabetes mellitus in a large sample of community-based United States residents.

\begin{tabular}{|c|c|c|c|}
\hline Variables & Prevalence odds ratio & 95\% confidence interval & $p$ \\
\hline \multicolumn{4}{|l|}{ Race } \\
\hline Non-Hispanic whites & 1.00 & Reference & Reference \\
\hline Non-Hispanic blacks & 1.45 & $1.30-1.62$ & $<0.001$ \\
\hline Hispanics & 0.98 & $0.87-1.09$ & 0.68 \\
\hline \multicolumn{4}{|l|}{ Family income } \\
\hline$\leq \$ 20,000$ & 1.00 & Reference & Reference \\
\hline$>\$ 20,000$ & 0.59 & $0.54-0.64$ & $<0.001$ \\
\hline \multicolumn{4}{|l|}{ Insurance status } \\
\hline Yes & 1.00 & Reference & Reference \\
\hline No & 1.00 & $0.88-1.14$ & 0.950 \\
\hline \multicolumn{4}{|l|}{ Education } \\
\hline$<$ High school & 1.00 & Reference & Reference \\
\hline High school & 0.39 & $0.36-0.42$ & $<0.001$ \\
\hline Some college & 0.22 & $0.19-0.25$ & $<0.001$ \\
\hline$\geq$ Bachelor's degree & 0.20 & $0.17-0.24$ & $<0.001$ \\
\hline \multicolumn{4}{|l|}{ Age } \\
\hline$\leq 50$ years & 1.00 & Reference & Reference \\
\hline$>50$ & 6.36 & $5.61-7.21$ & $<0.001$ \\
\hline \multicolumn{4}{|l|}{ Body mass index } \\
\hline Underweight & 1.00 & Reference & Reference \\
\hline Normal weight & 0.82 & $0.55-1.21$ & 0.320 \\
\hline Overweight & 1.68 & $1.13-2.49$ & 0.010 \\
\hline Obese & 4.08 & $2.76-6.04$ & $<0.001$ \\
\hline \multicolumn{4}{|l|}{ Smoking } \\
\hline No & 1.00 & Reference & Reference \\
\hline Yes & 1.90 & $1.63-2.22$ & $<0.001$ \\
\hline \multicolumn{4}{|l|}{ Alcohol } \\
\hline No & 1.00 & Reference & Reference \\
\hline Yes & 1.32 & $1.21-1.44$ & $<0.001$ \\
\hline \multicolumn{4}{|l|}{ Physical activities } \\
\hline No & 1.00 & Reference & Reference \\
\hline Yes & 0.67 & $0.60-0.74$ & $<0.001$ \\
\hline \multicolumn{4}{|l|}{ Marital status } \\
\hline Nonmarried & 1.00 & Reference & Reference \\
\hline Married & 0.89 & $0.82-0.96$ & 0.004 \\
\hline
\end{tabular}

plausible and supports racial variation in diabetes mellitus, given that Caucasians were more likely to acquire higher education compared to Hispanic and African Americans. Again, this finding does not hold for Hispanics since Hispanics had the lowest education but a slightly lower prevalence of diabetes mellitus compared to Caucasians. In general, it is logical to expect higher education to be associated with lower prevalence of diabetes mellitus because individuals who are educated are more likely to understand the risk factors for diabetes mellitus and apply this knowledge in controlling behavior towards risk factors reduction, namely, alcohol, smoking, and physical inactivity. Lower education level has been associated with increased risk of diabetes mellitus and other chronic diseases [29-32], and our results clearly support these previous data [33-40].

We have also demonstrated that the prevalence of diabetes mellitus is associated with current smoking, alcohol, physical activity, body mass index, and age. NonHispanic whites were more likely to smoke compared with either non-Hispanic blacks or Hispanics. Smoking is a risk factor in hypertension since it results in the constriction of the blood vessels, thus increasing peripheral resistance, and elevating the blood pressure. Smoking may play a role in DM given the nexus between DM and hypertension. Compared with other racial/ethnic groups, Hispanics were less likely to exercise or be involved in physical activities. 
TABLE 4: Unconditional multivariable logistic regression model of the effect of race/ethnicity on diabetes mellitus prevalence in a large sample of community-based United States residents.

\begin{tabular}{|c|c|c|c|}
\hline Variables & Prevalence odds ratio & 95\% confidence interval & $p$ value \\
\hline \multicolumn{4}{|l|}{ Race } \\
\hline Non-Hispanic whites & 1.00 & Reference & Reference \\
\hline Non-Hispanic blacks & 1.30 & $1.15-1.47$ & $<0.001$ \\
\hline Hispanics & 1.13 & $0.99-1.28$ & 0.06 \\
\hline \multicolumn{4}{|l|}{ Family income } \\
\hline$\leq \$ 20,000$ & 1.00 & Reference & Reference \\
\hline$>\$ 20,000$ & 0.66 & $0.60-0.73$ & $<0.001$ \\
\hline \multicolumn{4}{|l|}{ Education } \\
\hline$<$ High school & 1.00 & Reference & Reference \\
\hline High school & 0.92 & $0.83-1.02$ & 0.120 \\
\hline Some college & 0.63 & $0.54-0.74$ & $<0.001$ \\
\hline$\geq$ Bachelor's degree & 0.71 & $0.59-0.87$ & 0.001 \\
\hline \multicolumn{4}{|l|}{ Age } \\
\hline$\leq 50$ years & 1.00 & Reference & Reference \\
\hline$>50$ years & 6.13 & $5.36-7.01$ & $<0.001$ \\
\hline \multicolumn{4}{|l|}{ Body mass index } \\
\hline Underweight & 1.00 & Reference & Reference \\
\hline Normal weight & 0.87 & $0.58-1.31$ & 0.510 \\
\hline Overweight & 1.61 & $1.08-2.41$ & 0.020 \\
\hline Obese & 3.90 & $2.61-5.82$ & $<0.001$ \\
\hline \multicolumn{4}{|l|}{ Smoking } \\
\hline No & 1.00 & Reference & Reference \\
\hline Yes & 1.30 & $1.19-1.43$ & $<0.001$ \\
\hline \multicolumn{4}{|l|}{ Alcohol } \\
\hline No & 1.00 & Reference & Reference \\
\hline Yes & 1.24 & $1.12-1.38$ & $<0.001$ \\
\hline \multicolumn{4}{|l|}{ Physical activities } \\
\hline No & 1.00 & Reference & Reference \\
\hline Yes & 0.95 & $0.85-1.06$ & 0.34 \\
\hline \multicolumn{4}{|l|}{ Marital status } \\
\hline Nonmarried & 1.00 & Reference & Reference \\
\hline Married & 0.97 & $0.89-1.07$ & 0.610 \\
\hline
\end{tabular}

Physical activity is known to lower blood pressure and to be protective against the development of diabetes mellitus. Exercise has been shown to result in the expression of the genes that regulate insulin receptors, thus enhancing plasma glucose reuptake, and normalizing glycemic index [41]. Elevated BMI is associated with diabetes mellitus due to the extra load placed on the myocardium as result of increased cardiac contractibility which leads to increased heart rate and stroke volume, hence elevating the cardiac output and the subsequence increase in the blood pressure. Similarly, the nexus between hypertension and elevated blood glucose level may explain the observed relationship between BMI and glucose intolerance [42]. A direct association between overweight and DM is the explained insulin receptors insensitivity observed among overweight individuals. Paradoxically, whereas Hispanics were more likely to be overweight compared with non-Hispanic whites, the prevalence of DM was lowest among Hispanics. Diabetes mellitus increases with advancing age due to the development of arterial plagues leading to arteriosclerosis, hence increasing peripheral resistance through the stiffening of the blood vessels. Increased risk of DM among older individuals may be due to decreased sensitivity to insulin receptors observed in aging process. Hispanics were more likely to be in the younger age group where diabetes mellitus is less prevalent. This may explain in part why DM was less prevalent among this racial/ethnic group compared with non-Hispanic whites and non-Hispanic blacks [42-44].

This study showed African American with the highest prevalence of diabetes mellitus, indicative of racial/ethnic disparities in diabetes mellitus in this sample. Race is a complex phenomenon, not very clearly understood. The highest prevalence of diabetes mellitus among African Americans may be due to biologic variation, genetic differences, and 
variance in geographic environment, nutrition/dietary differences, or in gene-environment interaction. The covariates that independently predicted diabetes mellitus have been shown to differ between African Americans/blacks and Caucasians as well as Hispanics. These covariates should very well explain or remove the disparities in diabetes mellitus between African American/blacks and Caucasians if properly controlled in a statistical model, as achieved in this study. It is therefore unclear why this variation in diabetes mellitus persisted between African Americans and Caucasians after controlling for these potential confounding variables. However, it is plausible to suspect that there are other factors determining diabetes mellitus that are not available for adjustment in the relationship between this outcome variable (DM) and race/ethnicity [43, 45].

Despite the strength of our study (large sample size), this study is not without limitations. First, as a cross-sectional design, it is difficult to establish a temporal sequence, implying a clear direction on the causal pathway in the relationship between diabetes mellitus and race as well as other explanatory variables. However, it is unlikely that temporal sequence is mismatched in the cause and effect relationship between race/ethnicity and diabetes mellitus, since race preceded the development of diabetes mellitus. Second, because we recoded variables that were originally collected as continuous into categorical level, we might have introduced misclassification bias into our findings. Third, like most epidemiologic studies, these findings may be influenced by unmeasured and residual confounding since no statistical modeling no matter how sophisticated can remove all confounding in a data [46].

In summary, in this sample of noninstitutionalized or community-based United States residence, the prevalence of diabetes mellitus was highest among African Americans. Secondly, the observed racial/ethnic disparities were unexplained by life style and sociodemographic variables. This study is suggestive of the need to explore other potential risk factors in diabetes mellitus using prospective designs.

\section{References}

[1] R. A. Miech, J. Kim, C. McConnell, and R. F. Hamman, "A growing disparity in diabetes-related mortality U.S. trends, 1989-2005," American Journal of Preventive Medicine, vol. 36, no. 2, pp. 126-132, 2009.

[2] National Institute of Diabetes and Digestive and Kidney Diseases, "National Diabetes Statistics Fact Sheet: general information and national estimates on diabetes in the United States," U.S. Department of Health and Human Services, National Institute of Health, Bethesda, Md, USA, 2005, http://diabetes.niddk.nih.gov/dm/pubs/statistics/index.aspx.

[3] "The National Diabetes Education Program of the National Institute of Diabetes and Digestive and Kidney Diseases, (NIDDK)," National Institutes of Health, Department of Health and Human Services, 2005 reports.

[4] Centers for Disease Control and Prevention, "Disease Burden and Risk Factors," 2006, http://www.cdc.gov/omhd/amh/dbrf .htm.

[5] E. J. Mayer-Davis, R. A. Bell, D. Dabelea et al., "The many faces of diabetes in American youth: type 1 and type 2 diabetes in five race and ethnic populations: the SEARCH for diabetes in youth study," Diabetes Care, vol. 32, no. 2, pp. S99-S101, 2009.

[6] R. N. Anderson and B. L. Smith, "Deaths: leading causes for 2002.," National Vital Statistics Reports, vol. 53, no. 17, pp. 189, 2005.

[7] A. Jemal, E. Ward, Y. Hao, and M. Thun, "Trends in the leading causes of death in the United States, 1970-2002," Journal of the American Medical Association, vol. 294, no. 10, pp. 1255-1259, 2005.

[8] L. E. Barker, K. A. Kirtland, E. W. Gregg, L. S. Geiss, and T. J. Thompson, "Geographic distribution of diagnosed diabetes in the U.S.: a diabetes belt," American Journal of Preventive Medicine, vol. 40, no. 4, pp. 434-439, 2011.

[9] National Center for Health Statistics, "Health, United States, 2005, with Chartbook on Trends in the Health of Americans," Hyattsville, Md, USA.

[10] F. Zizi, A. Pandey, R. Murrray-Bachmann et al., "Race/ethnicity, sleep duration, and diabetes mellitus: analysis of the national health interview survey," American Journal of Medicine, vol. 125, no. 2, pp. 162-167, 2012.

[11] Centers for Disease Control and Prevention, "New Chartbook Examines Health Care Utilization in America Documents Major Trends and Shifts in Health Care," 2004, http://www.cdc .gov/nchs/pressroom/04facts/healthcare.htm.

[12] Centers for Disease Control and Prevention, "Prevalence of overweight and obesity among adults with diagnosed diabetes-United States, 1988-1994 and 1999-2002," Morbidity and Mortality Weekly Report, vol. 53, no. 45, pp. 1066-1068, 2004.

[13] T. D. Sequist, G. M. Fitzmaurice, R. Marshall et al., "Cultural competency training and performance reports to improve diabetes care for black patients: a cluster randomized, controlled trial," Annals of Internal Medicine, vol. 152, no. 1, pp. 40-46, 2010.

[14] National Diabetes Education Program, "The Diabetes Epidemic Among African Americans," 2005, http://www.ndep .nih.gov/media/fs_africanam.pdf.

[15] N. B. Anderson, R. A. Bulatao, and B. Cohen, Critical Perspectives on Racial and Ethnic Differences in Health in late Life, National Academies Press, Washington, DC, USA, 2004.

[16] K. Seeleang, "Genetic disparities in the development of type 2 diabetes among African Americans," Journal of the American Academy of Nurse Practitioners, vol. 23, no. 9, pp. 473-478, 2011.

[17] Institute of Medicine, "Unequal Treatment: Confronting Racial and Ethnic Disparities in Health Care," 2002, http:// www.nap.edu/openbook/030908265X/html/80.html.

[18] Agency for Healthcare Research and Quality, "National Healthcare: Disparities Report," 2004, http://www.ahrq.gov/.

[19] N. E. Adler and K. Newman, "Socioeconomic disparities in health: pathways and policies," Health Affairs, vol. 221, no. 2, pp. 60-76, 2000.

[20] National Institutes of Health, "Clinical Guidelines on the Identification, Evaluation, and Treatment of Overweight and Obesity in Adults," 1998, http://www.nhlbi.nih.gov/guidelines/obesity/ob\%5Fhome.htm.

[21] J. E. Stewart, S. E. Battersby, A. Lopez-De Fede, K. C. Remington, J. W. Hardin, and K. Mayfield-Smith, "Diabetes and the socioeconomic and built environment: geovisualization of disease prevalence and potential contextual associations using ring maps," International Journal of Health Geographics, vol. 10, article no. 18, 2011. 
[22] N. E. Adler and J. M. Ostrove, "Socioeconomic status and health: What we know and what we don't," Annals of the New York Academy of Sciences, vol. 896, pp. 3-15, 1999.

[23] K. Fiscella, P. Franks, M. R. Gold, and C. M. Clancy, "Inequality in quality: addressing socioeconomic, racial and ethnic disparities in health care," Journal of the American Medical Association, vol. 283, no. 19, pp. 2579-2584, 2000.

[24] S. L. Botman, T. F. Moore, and C. L. Moriarity, "Design and Estimation for the National Health Interview Survey, 19952004," Vital and Health Statistics. Series 2, no. 130, pp. 1-31, 2000.

[25] C. Y. Osborn, H. W. Trott, M. S. Buchowski et al., "Racial disparities in the treatment of depression in low-income persons with diabetes," Diabetes Care, vol. 33, no. 5, pp. 1050-1054, 2010.

[26] R. E. Hurley, H. H. Pham, and G. Claxton, "A widening rift in access and quality: growing evidence of economic disparities," Health Affairs Web Exclusive, 2005, http://www.kff.org/uninsured/7415.cfm.

[27] M. Sims, A. V. Diez roux, S. Boykin et al., "The socioeconomic gradient of diabetes prevalence, awareness, treatment, and control among African Americans in the Jackson Heart Study," Annals of Epidemiology, vol. 21, no. 12, pp. 892-898, 2011.

[28] J. M. Mellor and J. Milyo, "Exploring the relationships between income inequality, socioeconomic status and health: a selfguided tour?" International Journal of Epidemiology, vol. 31, no. 3, pp. 685-687, 2002.

[29] J. Stone, "Race and healthcare disparities overcoming vulnerability," Theoretical Medicine and Bioethics, vol. 23, no. 6, pp. 499-518, 2002.

[30] J. A. Gazmararian, D. W. Baker, M. V. Williams et al., "Health literacy among medicare enrollees in a managed care organization," Journal of the American Medical Association, vol. 281, no. 6, pp. 545-551, 1999.

[31] E. J. MacLaughlin, C. L. Raehl, A. K. Treadway, T. L. Sterling, D. P. Zoller, and C. A. Bond, "Assessing medication adherence in the elderly: which tools to use in clinical practice?" Drugs and Aging, vol. 22, no. 3, pp. 231-255, 2005.

[32] D. Schillinger, J. Piette, K. Grumbach et al., "Closing the loop: physician communication with diabetic patients who have low health literacy," Archives of Internal Medicine, vol. 163, no. 1, pp. 83-90, 2003.

[33] M. V. Williams, D. W. Baker, R. M. Parker, and J. R. Nurss, "Relationship of functional health literacy to patients' knowledge of their chronic disease: a study of patients with hypertension and diabetes," Archives of Internal Medicine, vol. 158, no. 2, pp. 166-172, 1998.

[34] E. J. Nicklett, "Socioeconomic status and race/ethnicity independently predict health decline among older diabetics," $B M C$ Public Health, vol. 11, Article ID 684, 2011.

[35] D. Calvin, L. Quinn, B. Dancy et al., "African Americans' perception of risk for diabetes complications," Diabetes Educator, vol. 37, no. 5, pp. 689-698, 2011.

[36] K. Seeleang, "Genetic disparities in the development of type 2 diabetes among African Americans," Journal of the American Academy of Nurse Practitioners, vol. 23, no. 9, pp. 473-478, 2011.

[37] N. A. Allen, G. D. Melkus, and D. A. Chyun, "Physiological and behavioral factors related to physical activity in black women with type 2 diabetes mellitus," Journal of Transcultural Nursing, vol. 22, no. 4, pp. 376-385, 2011.

[38] T. D. Sequist, G. M. Fitzmaurice, R. Marshall et al., "Cultural competency training and performance reports to improve diabetes care for black patients: a cluster randomized, controlled trial," Annals of Internal Medicine, vol. 152, no. 1, pp. 40-46, 2010.

[39] M. E. Peek, H. Tang, G. C. Alexander, and M. H. Chin, "National prevalence of lifestyle counseling or referral among African-Americans and whites with diabetes," Journal of General Internal Medicine, vol. 23, no. 11, pp. 1858-1864, 2008.

[40] A. Yeboah-Korang, A. Kleppinger, and R. H. Fortinsky, "Racial and ethnic group variations in service use in a national sample of medicare home health care patients with type 2 diabetes mellitus," Journal of the American Geriatrics Society, vol. 59, no. 6, pp. 1123-1129, 2011.

[41] L. E. Egede, M. Gebregziabher, K. J. Hunt et al., "Regional, geographic, and racial/ethnic variation in glycemic control in a national sample of veterans with diabetes," Diabetes Care, vol. 34, no. 4, pp. 938-943, 2011.

[42] A. Shah, N. E. Stotland, Y. W. Cheng, G. A. Ramos, and A. B. Caughey, "The association between body mass index and gestational diabetes mellitus varies by race/ethnicity," American Journal of Perinatology, vol. 28, no. 7, pp. 515-520, 2011.

[43] O. K. Duru, R. B. Gerzoff, J. V. Selby et al., "Identifying risk factors for racial disparities in diabetes outcomes: the translating research into action for diabetes study," Medical Care, vol. 47, no. 6, pp. 700-706, 2009.

[44] C. R. Horowitz, J. Z. Goldfinger, S. E. Muller et al., "A model for using community-based participatory research to address the diabetes epidemic in East Harlem," Mount Sinai Journal of Medicine, vol. 75, no. 1, pp. 13-21, 2008.

[45] G. S. Magwood, C. Jenkins, and J. Zapka, "Validation of diabetes health-related quality-of-life instruments using cognitive interviewing with older African Americans," Journal of Nursing Measurement, vol. 17, no. 3, pp. 195-220, 2009.

[46] L. Holmes, W. Chan, Z. Jiang, and X. L. Du, "Effectiveness of androgen deprivation therapy in prolonging survival of older men treated for locoregional prostate cancer," Prostate Cancer and Prostatic Diseases, vol. 10, no. 4, pp. 388-395, 2007. 


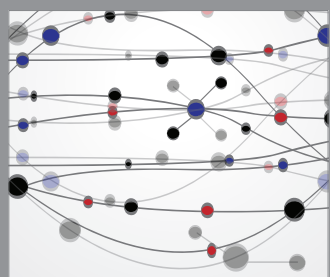

The Scientific World Journal
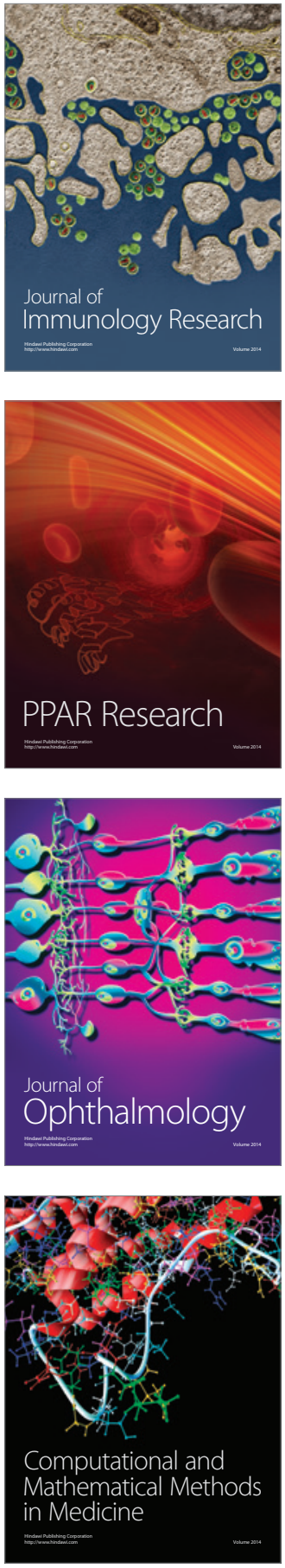

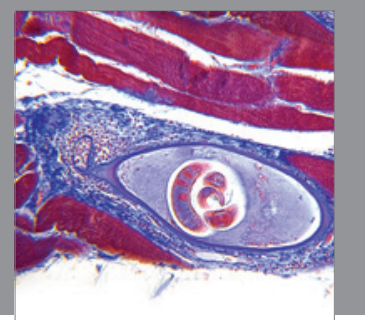

Gastroenterology

Research and Practice
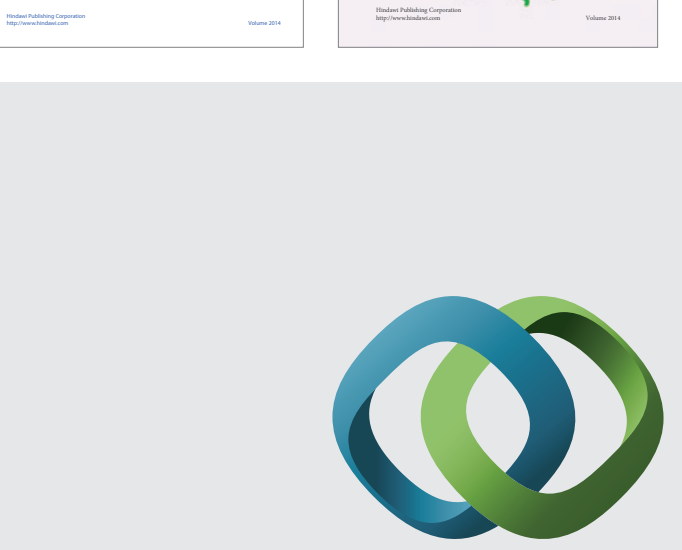

\section{Hindawi}

Submit your manuscripts at

http://www.hindawi.com
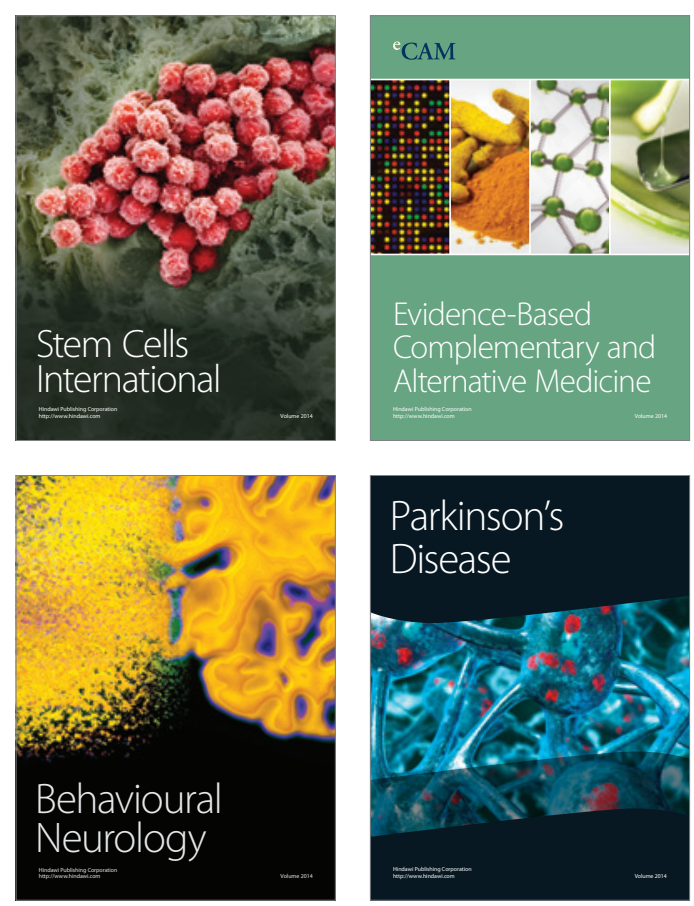

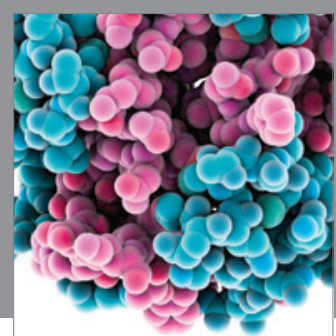

Journal of
Diabetes Research

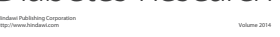

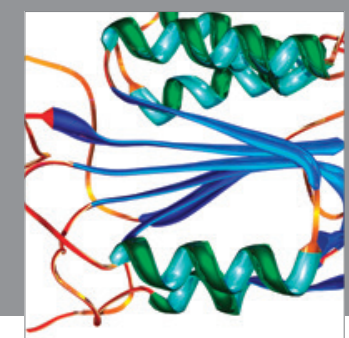

Disease Markers
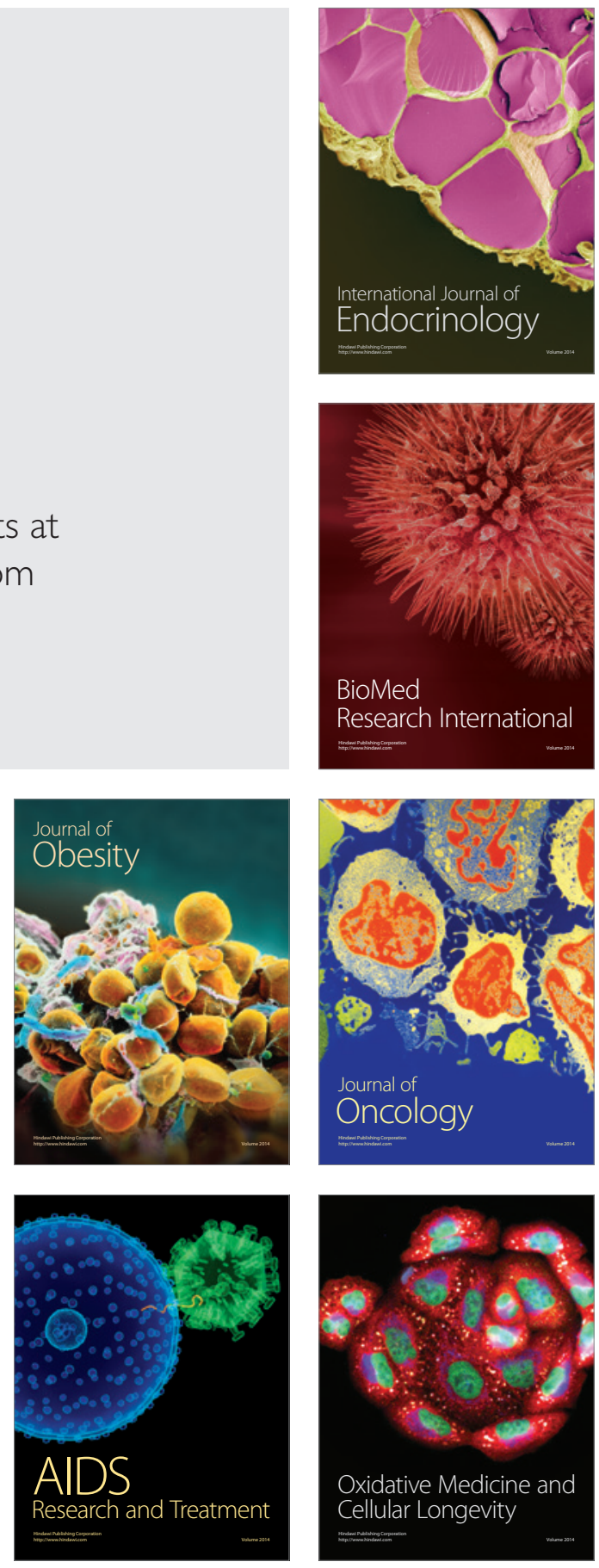